\title{
CAPÍTULO 42: ESCANEAMENTO POR BIOIMPEDÂNCIA ELÉTRICA EM LEITE: EXPLORANDO A TÉCNICA
}

\section{CHAPTER 42: ELECTRIC MILK BIOIMPEDANCE SCANNING: EXPLORING THE TECHNIQUE}

\author{
Ana Maria Geller ${ }^{1}$; Luciano Carvalho Ayres²; Claudia Wollmann Carvalho ${ }^{3}$; Renato Hartwig \\ Neuenfeld ${ }^{4}$; Wemerson de Castro Oliveira ${ }^{5}$
}

\begin{abstract}
Resumo
O leite é um produto alimentício de alto valor nutritivo e muito versátil na agroindústria de alimentos. Sua cadeia produtiva movimenta valores significativos, sendo necessário constante controle de qualidade para coibir falsificações e fraudes. Neste sentido, pesquisadores têm se dedicado a desenvolver métodos para análise do leite, bem como para identificar as diversas adulterações deste produto. A proposta deste artigo foi analisar sistematicamente publicações em revistas científicas, nas quais a bioimpedância foi utilizada como técnica para analisar o leite, selecionadas das principais plataformas de busca nos últimos 5 anos. A bioimpedância tem sido utilizada para detectar e monitorar muitos parâmetros e processos biológicos, com a vantagem de ser uma técnica relativamente barata e não invasiva. Em se tratando do leite, os trabalhos analisados, indicaram que a técnica tem se mostrado uma ferramenta promissora para a detecção e quantificação de diversos parâmetros físicos, químicos e biológicos, utilizados na determinação da qualidade do leite bovino, tanto para controle como monitoramento de eventuais alterações na sua composição. Contudo, por ser uma técnica nova no setor, sua utilização para a análise de rotina ainda implica na necessidade de maior pesquisa.
\end{abstract}

Palavras-Chave: Leite bovino, Impedância, Análise sistemática.

\begin{abstract}
Milk is a food product of high nutritional value and very versatile in the food industry. Its production chain moves values, requiring constant quality control for counterfeiting and fraud to prevent. In this sense, researchers have been dedicated to developing methods for analyzing milk, as well as to identify the various adulterations of this product. The proposed article was systematically analyzed publications of these scientific journals, in which a bioimpedance was used as a technique to analyze milk, selected from the main search platforms in the last 5 years. Bioimpedance has been used to detect and monitor many biological parameters and processes, with the advantage of being a relatively inexpensive and non-invasive technique. In the case of milk, the forced labor indicated that the technique has been specified as a promising tool for the detection and quantification of several physical, chemical and biological factors used in determining the quality of bovine milk, both for control and monitoring of strength. changes in

\footnotetext{
1 Doutora em Química Analítica Ambiental, Instituto Federal de Educação, Ciência e Tecnologia Sul-riograndense (IFSul), anageller@ifsul.edu.br lucianoayres@ifsul.edu.br

3 Doutora em Química, Instituto Federal de Educação, Ciência e Tecnologia Sul-rio-grandense (IFSul), claudiacarvalho@ifsul.edu.br

${ }^{4}$ Mestre em Engenharia Elétrica, Instituto Federal de Educação, Ciência e Tecnologia Sul-rio-grandense (IFSul), renatoneuenfeld@ifsul.edu.br

${ }^{5}$ Doutor em Microbiologia Agrícola, Instituto Federal de Educação, Ciência e Tecnologia Sul-rio-grandense

(IFSul),wemersonoliveira@ifsul.edu.br
}

${ }_{2}^{2}$ Mestre em Engenharia Elétrica, Instituto Federal de Educação, Ciência e Tecnologia Sul-rio-grandense (IFSul),
\end{abstract}


its composition. However, as it is a new technique in the sector, its use for routine analysis still implies the need for further research.

Keywords: Bovine milk, Impedance, Systematic analysis.

\section{Introdução}

Leite, é uma combinação de elementos sólidos, como lipídios (gordura), carboidratos, proteínas, sais minerais e vitaminas em $87 \%$ de água (BRITO et al., 2020). Ele é um dos produtos mais versáteis da agroindústria de alimentos, podendo ser consumido na sua forma original ou ser transformado em derivados (RENTERO, 2018).

Atualmente, no Brasil, estima-se que a captação total de leite comercializado no ano de 2019, foi de 24,97 bilhões de litros, existindo 1.171.190 fazendas leiteiras. A região Sudeste possui o maior volume de produção, já a região Centro-Oeste apresentou o maior incremento em relação a 2018 (17,33\%), seguida da Região Sul (13,48\%) (MILKPOINT, 2020). A cadeia produtiva do leite está presente em todo o Brasil, gerando um faturamento, em 2017, de R \$ 70,2 bilhões para a indústria de laticínios no país, crescimento de 4\% em relação a 2016 (RENTERO, 2018). Entre os produtos de maior consumo, está o leite longa vida ou UHT (Ultra Hight Temperature) ou, traduzindo, leite UAT (ultra alta temperatura). Tal fato, segundo a Associação Brasileira do Leite Longa Vida - ABVL, se deve pela preferência no consumo por cerca de $80 \%$ da população, decorrente de sua praticidade de armazenamento sem a necessidade de refrigeração e estendido tempo de prateleira (BERTOLINI; ROSSI, 2017; OLIVEIRA et al., 2019).

Para garantir a qualidade do leite e seus derivados e ainda coibir fraudes, o governo brasileiro, elabora e atualiza as diretrizes de controle. Atualmente, a instrução normativa $\mathrm{n}^{\circ}$ 30/2018, do Ministério da Agricultura, Pecuária e Abastecimento - MAPA, oficializa o Manual de Métodos Oficiais para Análise de Alimentos de Origem Animal (BRASIL, 2018). O manual de 140 páginas, descreve com precisão como cada análise deve ser realizada, fazendo distinção entre análises físico-químicas e microbiológicas. O capítulo 2 é destinado a descrição referente ao leite e produtos lácteos. As análises recomendadas são baseadas no preparo de diferentes soluções, empregando titulações, reações e outras técnicas trabalhosas que demandam tempo e experiência do analista (BRASIL, 2017). Nesse sentido, a procura por novas técnicas de análise para a indústria alimentícia, particularmente, para a promoção da qualidade do leite, tem sido uma constante e entre elas, neste artigo abordaremos, com especial atenção, a impedância.

A impedância é um termo comum no campo da eletricidade e denota a razão entre a tensão e a corrente elétrica estabelecida em um componente ou sistema. O conceito de 
bioimpedância trata das propriedades elétricas de um tecido biológico, como condutividade, permissividade, resistência, capacitância e indutância (PLIQUETT, 2010). Os tecidos biológicos são formados por células de características semelhantes envoltas por um líquido eletrolítico. Tais células são combinações de moléculas organizadas e compostas por diversos componentes químicos, tanto inorgânicos como água e sais, como os orgânicos: ácidos, carboidratos e proteínas (QUILLFELDT, 2005; PEREIRA, 2009). Entre esses tecidos, pode haver a circulação de corrente elétrica, através de íons de compostos dissociados no meio aquoso existente, tanto dentro como fora da célula, uma vez que nos tecidos biológicos não há disponibilidade de elétrons livres como ocorre nas bandas de valência dos metais condutores (QUILLFELDT, 2005). Assim, a bioimpedância elétrica pode ser definida como o grau de impedimento a passagem da corrente elétrica em um meio biológico, cuja medição é realizada através de eletrodos metálicos. O modelo elétrico de um meio biológico pode ser representado por um elemento resistivo, que depende majoritariamente da composição química do meio extracelular, e de um elemento capacitivo decorrente das membranas celulares e do conteúdo intracelular.

Neste contexto, a associação destes elementos forma a chamada bioimpedância que varia com a frequência $(f)$, em hertz $(\mathrm{Hz})$, da fonte de excitação aplicada e com o tipo de tecido (PEREIRA, 2009). A influência da frequência de excitação no comportamento da corrente elétrica nos tecidos biológicos é ilustrada na Figura 1 (a), ou seja, para frequências inferiores a $100 \mathrm{kHz}$, a corrente predominante circula no espaço extracelular e para frequências maiores a corrente atravessa a membrana celular e percorre o espaço intracelular (GRIMNES; MARTINSEN, 2000). Assim, um tecido biológico pode ser modelado por um circuito elétrico equivalente conforme ilustrado na Figura 1 (b), onde o espaço extracelular pode ser representado por um resistor $\left(R_{e}\right)$ em paralelo com um circuito-série composto pelo capacitor $\left(C_{m}\right)$ e o resistor $\left(R_{i}\right)$, referentes à membrana celular e ao meio intracelular, respectivamente (HOLDER, 2004; TAKA, 2008).

Como uma forma de excitação dos tecidos biológicos e medição destas propriedades elétricas, é necessária a construção de um conjunto de eletrodos dispostos e conectados a um circuito eletrônico, responsável pela injeção de corrente elétrica e medição de tensão, denominado canal de medição (MORO; PORTO, 2015; PEREIRA, 2009). Os valores de impedância do tecido biológico, compreendidos entre os eletrodos de medição, são geralmente representados por um número complexo $Z$, dado em ohms $(\Omega)$, composto por uma parte real, $\operatorname{Re}\{Z\}$, e outra imaginária, $\operatorname{Im}\{Z\}$. A parte real corresponde à componente resistiva $\mathrm{R}$ da impedância $Z$, enquanto a imaginária sua reatância capacitiva, $X_{C}$. Neste caso, os números complexos em sua forma polar representam a relação de amplitude (magnitude ou módulo de 
$\mathrm{Z}$, simbolizado por $|\mathrm{Z}|$, em ohms) e atraso entre os sinais alternados de tensão e corrente elétrica (fase de Z, simbolizado por um ângulo $\theta$, em graus). Usualmente, os dados de bioimpedância medidos são plotados em um plano de impedância complexo como o da figura 2 , de acordo com o modelo de Cole-Cole (GRIMNES; MARTINSEN, 2000). Conforme a frequência $\omega=$ $2 \pi f$, em rad/s, do sinal de excitação aumenta, o ângulo de fase $\theta$ eleva-se gradualmente, à medida que a corrente passa a fluir pela resistência intracelular. Para altas frequências, a reatância capacitiva da membrana celular torna-se desprezível e a corrente flui completamente através do ambiente intracelular e extracelular. Assim, a impedância equivalente total torna-se, mais uma vez, puramente resistiva. Em situações práticas, o gráfico de Cole-Cole observado é um semicírculo, como o da Figura 2.

Figura 1. (a) Comportamento da corrente elétrica em tecidos biológicos em função da frequência. (b) Circuito elétrico equivalente de uma célula.

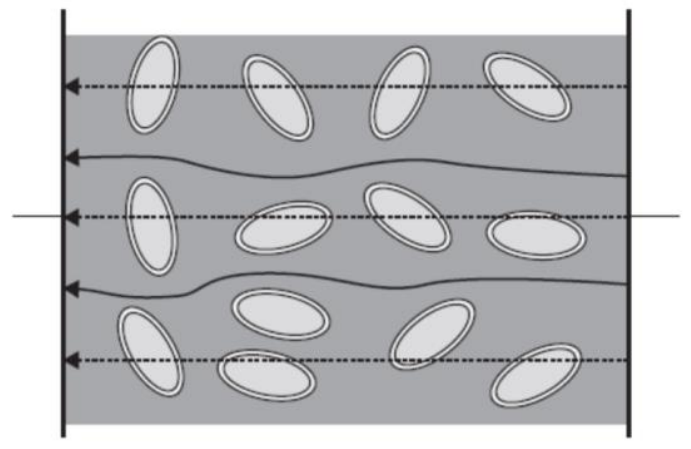

Alta frequência

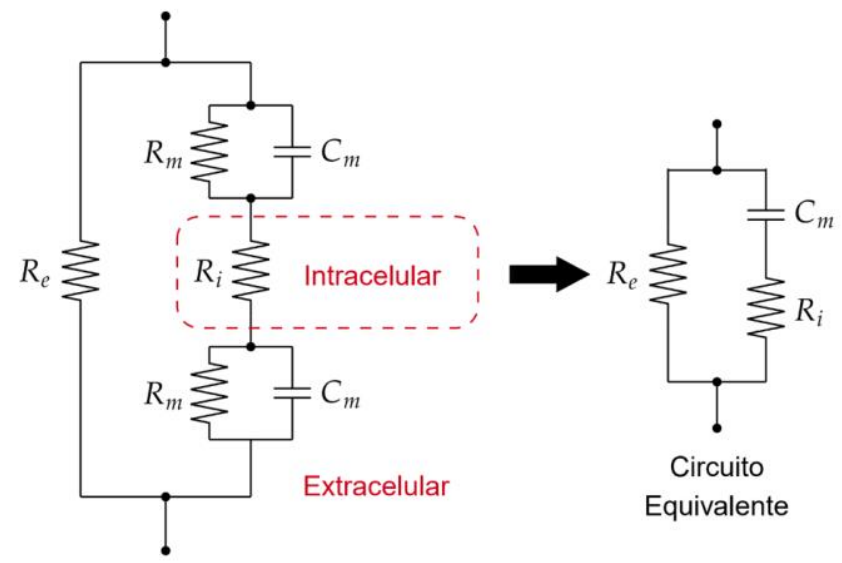

(a)

(b)

Fonte: (a) Adaptado de Porto et al., 2020; (b) Adaptado de Holder, 2004.

Figura 2. Gráfico de Cole-Cole para bioimpedância.

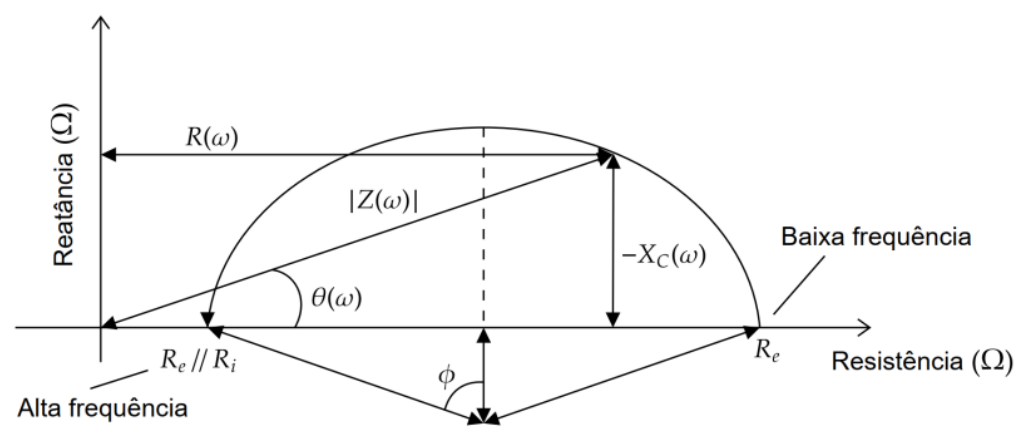

Fonte. Adaptado de Grimnes; Martinsen, 2000. 
Sendo assim, geralmente, o canal de medição de bioimpedância é composto de um gerador de onda senoidal, um condicionador de sinal para ajustar o nível de tensão de saída do bloco gerador, uma fonte de corrente controlada por tensão, um bloco para leitura das tensões, um bloco demodulador fase-quadratura, que tem a finalidade de fornecer o valor real e imaginário da impedância elétrica, e por fim, um filtro passa-baixa. Um diagrama simplificado do canal de medição pode ser visto na Figura 3.

Figura 3. Diagrama simplificado de um canal de medição de bioimpedância.

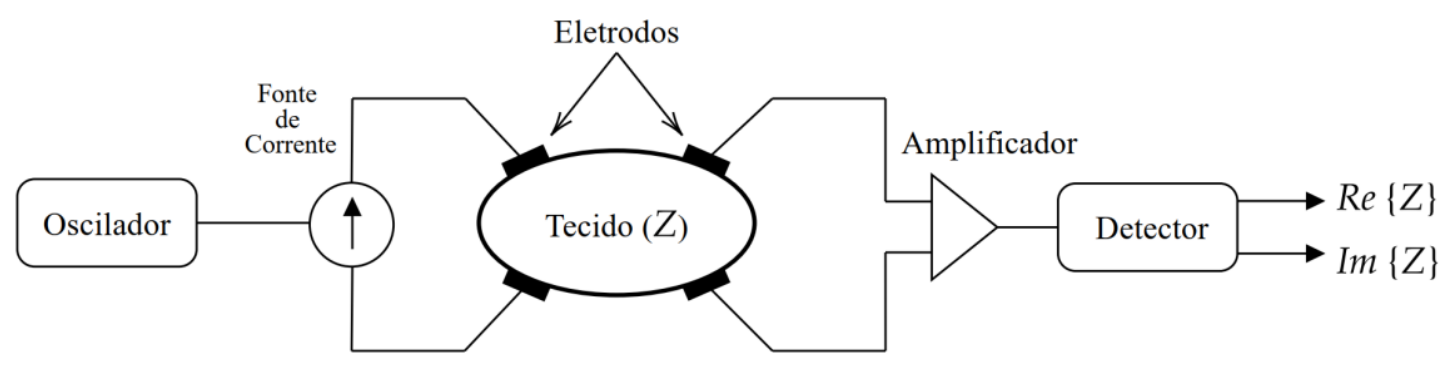

Fonte. Adaptado de Porto, 2009.

A maioria das fontes de corrente utilizadas em medidas de bioimpedância é chamada de conversor tensão/corrente, pois a corrente na saída é proporcional à tensão da entrada. Idealmente, uma fonte de corrente $I_{S}$ deve possuir impedância de saída $Z_{O}$ infinita, assim a corrente $I_{L}$ fornecida para a carga é constante (Figura 4a). Porém, as fontes de corrente reais possuem uma impedância de saída finita e podem ser representadas por um resistor $R_{O}$ em paralelo com um capacitor $C_{O}$, conforme indicado na figura $4 \mathrm{~b}$. A existência desta impedância de saída causa erros sistemáticos nas medidas de bioimpedância e, portanto, deve ser caracterizada previamente. Cabe ressaltar, ainda, que existem variações no projeto de canais de medição, quanto ao tipo de fonte de excitação, quantidade e construção dos eletrodos e topologias dos circuitos eletrônicos envolvidos no canal de medição.

A técnica da impedância, por ser não invasiva, relativamente barata e por possibilitar a detecção e o monitoramento de vários parâmetros e processos biológicos já é bem utilizada na área da medicina (TAKA, 2008; YÚFERA; CAÑETE; DAZA, 2011; SANCHEZ et al., 2011). Em alimentos, há trabalhos que remontam a década de 90 (NEAVES; WADDELLl; PRENTICE, 1988; DEAK; BEUCHAT, 1993; RUSSELL; FLETCHER; COX, 1994), porém, recentemente sua utilização foi retomada, principalmente para a análise de vegetais e frutas (BAKR et al., 2016; FREEBORN et al., 2017; EL KHALED et al., 2017; AL ALI et al., 2018). Ainda é importante destacar que aspectos particulares da técnica implicam numa nomenclatura 
diferenciada. Quando há variação de frequência os termos mais empregados são Espectroscopia de Impedância Elétrica (Electrical Impedance Spectroscopy - EIS) ou Espectroscopia de bioimpedância (Bioimpedance Spectroscopy ou Bioelectrical Impedance Spectroscopy - BIS). O EIS é bem usual, mesmo nos trabalhos de bioimpedância. Já quando a frequência de medida é fixa, a técnica é conhecida por Análise de Bioimpedância Elétrica (Bioelectrical Impedance Analysis - BIA). Contudo, este artigo de revisão estará focado em apresentar a utilização da metodologia de espectroscopia de bioimpedância em leite bovino elucidando suas potencialidades de análise, já que este alimento é muito consumido e, portanto, deve oferecer boa qualidade, bem como envolve uma cadeia produtiva extensa e mundialmente estruturada, com representação de norte ao sul do Brasil e que, infelizmente, costuma ser objeto de fraudes.

Figura 4. Modelo de uma fonte de corrente (a) ideal, (b) real.

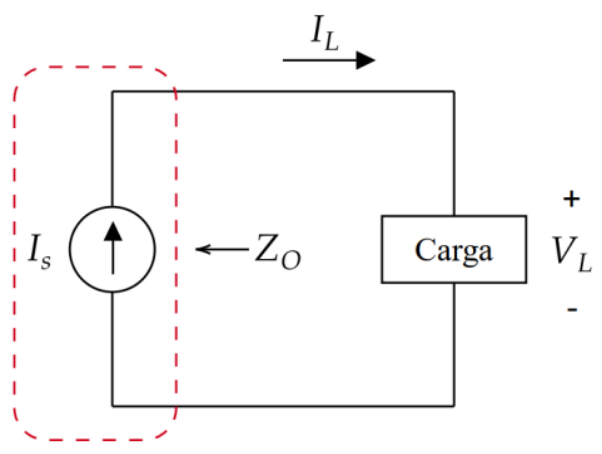

(a)

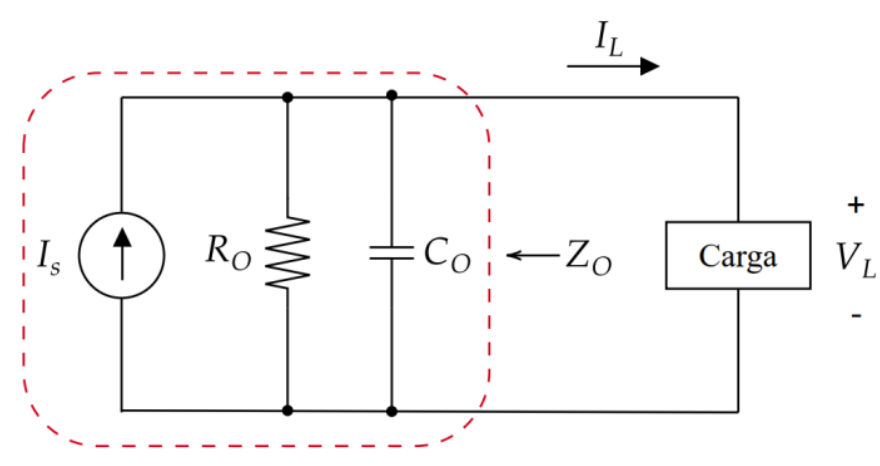

(b)

Fonte: Adaptado de Holder, 2004.

\section{Desenvolvimento}

A presente revisão sistemática considerou artigos elegíveis de estudos originais realizados com a temática "Utilização da metodologia de escaneamento por bioimpedância elétrica em leite bovino", publicados em inglês, espanhol ou português nos últimos cinco anos (2015-2020). Considerando os critérios de elegibilidade desta proposta, os artigos não originais como revisões, editoriais, cartas, comentários e capítulos de livros não foram considerados. As fontes de informações consideradas foram retiradas das bases de dados eletrônicas incluídas na Google Scholar, LILACS, PubMed, Science Direct, Scielo e Tripdatabase, a partir dos termos: "impedance", "bioimpedance", "milk" e "microbiology" cruzados um com o outro. A fase inicial de seleção dos artigos foi através da análise dos títulos, seguida do resumo e por último a leitura integral, sendo esta avaliação independente perpassando por um total de 25 artigos 
originais sobre a temática, sendo 7 excluídos por não apresentarem dados originais, ou seja, foram artigos de revisão, ou ainda apresentaram dados de outros tipos de leite animal (égua e cabra).

As pesquisas com a aplicação da metodologia de impedância elétrica têm crescido substancialmente nos últimos anos, principalmente voltadas para a área de análises de alimentos. Na plataforma PubMed o primeiro relato de citação sobre a impedância (impedance) foi em 1919 e, posteriormente, em 1977 surge a citação do termo bioimpedância (bioimpedance), sendo este último relacionado às propriedades elétricas de um tecido biológico (QUILLFELDT, 2005; PEREIRA, 2009). A utilização da técnica na área da saúde e de alimentos não é recente, citações datadas de 1947 foram identificadas em relação a impedância na medicina (impedance + medicine) e em alimentos (impedance + food) e 1967 na área de nutrição (impedance + nutrition) (PubMed). Atualmente, são encontradas 354.278 e 5.183 citações sobre o termo impedância e bioimpedância, respectivamente, na Science Direct.

No Quadro 1, apresenta-se o número de citações, dos últimos cinco anos, considerando os termos de busca e suas combinações, utilizados nesta revisão, nas diferentes plataformas. $\mathrm{O}$ conjunto dos termos impedance+milk foi o que apresentou maior número de citações em todas as plataformas. Observou-se que, substituindo o termo impedance por bioimpedance, nas combinações de palavras, o número de citações foi drasticamente reduzido. Considerando as plataformas que publicam somente artigos científicos, a Science Direct foi a que apresentou maior número de citações.

Observa-se um crescente aumento de citações ao longo dos anos, em publicações que relacionam a técnica de impedância/bioimpedância em análises físico-químicas e microbiológicas de leite, principalmente bovino (Quadro 1). Considerando os termos utilizados nas buscas realizadas e as duas plataformas mais acionadas para pesquisas de artigos originais, Science Direct e PubMed, é possível observar um aumento de citações de 2,0 e 1,3 vezes comparando o ano de 2020 com o de 2015, respectivamente. Deve-se ressaltar que no ano de 2020 o número de citações consideradas é somente referente ao primeiro semestre.

Ao final da busca, considerando os últimos 5 anos, foram analisados 18 artigos, dentre estes 9 (nove) publicado entre $2016(n=5)$ e $2017(n=4)$. Outra observação interessante, diz respeito ao tipo de revista onde os artigos foram publicados, 50\% dos trabalhos foram abordados em revistas específicas da área de engenharia elétrica, enquanto que os outros trabalhos foram publicados em revistas com ênfase em alimentos, microbiologia, ciência animal e química. Tal fato, pode estar associado a necessidade de conhecimento e aprimoramento do 
equipamento/técnica para a determinação da impedância, e por outro lado, revela a versatilidade da técnica em termos de aplicações.

Quadro 1. Número de citações entre os anos de 2015-2020 nos bancos de dados de diferentes plataformas.

\begin{tabular}{|c|c|c|c|c|c|c|c|}
\hline \multirow[b]{2}{*}{ Termos } & \multicolumn{7}{|c|}{ Plataformas pesquisadas } \\
\hline & $\begin{array}{l}\text { Google } \\
\text { Scholar }\end{array}$ & $\begin{array}{c}\text { Science } \\
\text { direct }\end{array}$ & PubMed & Scielo & TripDatabase & LILACS & Total \\
\hline Impedance+milk & 15000 & 2557 & 99 & 1 & 135 & 0 & 17792 \\
\hline Impedance+milk+microbiology & 2730 & 335 & 12 & 0 & 15 & 0 & 3092 \\
\hline Bioimpedance + milk & 1390 & 93 & 22 & 1 & 19 & 0 & 1525 \\
\hline Bioimpedance + milk + microbiology & 150 & 6 & 0 & 0 & 0 & 0 & 156 \\
\hline Total & 19270 & 2991 & 133 & 2 & 169 & 0 & \\
\hline Média & 4817,5 & 747,75 & 33,25 & 0,5 & 42,25 & 0 & \\
\hline \multirow{2}{*}{ Termos } & \multicolumn{7}{|c|}{ Science Direct } \\
\hline & 2015 & 2016 & 2017 & 2018 & 2019 & 2020 & Média \\
\hline Impedance+milk & 255 & 332 & 410 & 474 & 565 & 521 & 2557 \\
\hline Impedance+milk+microbiology & 34 & 44 & 61 & 61 & 62 & 73 & 335 \\
\hline Bioimpedance+milk & 16 & 10 & 15 & 13 & 22 & 17 & 93 \\
\hline Bioimpedance + milk + microbiology & 0 & 1 & 1 & 1 & 1 & 2 & 6 \\
\hline Total & 305 & 387 & 487 & 549 & 650 & 613 & \\
\hline Média & 76,25 & 96,75 & 121,75 & 137,25 & 162,5 & 153,25 & \\
\hline \multirow{2}{*}{ Termos } & \multicolumn{7}{|c|}{ PubMed } \\
\hline & 2015 & 2016 & 2017 & 2018 & 2019 & 2020 & Média \\
\hline Impedance+milk & 17 & 17 & 25 & 22 & 23 & 20 & 124 \\
\hline Impedance+milk+microbiology & 1 & 2 & 2 & 3 & 4 & 0 & 12 \\
\hline Bioimpedance+milk & 2 & 3 & 4 & 7 & 6 & 5 & 27 \\
\hline Bioimpedance + milk + microbiology & 0 & 0 & 0 & 0 & 0 & 0 & 0 \\
\hline Total & 20 & 22 & 31 & 32 & 33 & 25 & \\
\hline Média & 5 & 5,5 & 7,75 & 8 & 8,25 & 6,25 & \\
\hline
\end{tabular}

Fonte: Própria.

\section{Discussão}

O leite pode ser comercializado na forma cru ou "in natura", ou após sofrer processo térmico de pasteurização ou UHT, segundo as normativas contidas nas portarias n ${ }^{\circ}$ 146/1996 e n 3 370/1997 do MAPA (BRASIL, 1996; BRASIL, 1997). Contudo, é a relação constante entre seus componentes a base para os testes que objetivam apontar a ocorrência de problemas que alteram a composição do leite (BRITO et al., 2020). Na análise realizada, sete artigos apresentaram dados de impedância determinados em leite cru, seis utilizaram o leite tipo UHT e em seis trabalhos o tipo de leite não foi informado, o que dificulta a comparação entre 
trabalhos. É comum que as pesquisas apresentem dados de mais de um tipo de leite, diferenciado, principalmente, por tipo de processamento ou ainda teor de gordura. Ainda, a análise das publicações permite dizer que em dois artigos o objetivo era, através da impedância, avaliar a qualidade por características físico-químicas, oito tinham como foco combater adulteração e oito com avaliação química e biológica (Quadro 2).

Ao avaliar as metodologias utilizadas nos diferentes trabalhos, percebeu-se uma grande variação de temperatura de análise, sendo a maior temperatura $47^{\circ} \mathrm{C}$ (BANCALARI et al., 2016) em ensaios com verificação de atividade metabólica bacteriana, e a menor sendo $5^{\circ} \mathrm{C}$ (aproximadamente a temperatura utilizada na armazenagem e transporte) nos ensaios de análise de bioimpedância elétrica realizado por Schumacher e colaboradores (2019).

Apesar de quatro trabalhos citarem dados de condutividade (URIA et al., 2016; TRIPATHY et al., 2017; SCHUMACHER et al., 2019; SUDE \& GHODINDE, 2019), em nenhum deles foi mencionado o equipamento utilizado, para Sude \& Ghodinde (2019), a condutividade do leite puro foi de $4,65 \mathrm{mS}$, já do leite adulterado com ureia o valor passou para $4,58 \mathrm{mS}$ e com amido para $4,734 \mathrm{mS}$.

Percebe-se a busca pela otimização das pesquisas com impedância em análise de leite, pelo fato de oito trabalhos estarem usando equipamentos comerciais (LIU et al., 2015; LI et al., 2016; BANCALARI et al., 2016; TRIPATHY et al., 2017; DAS et al., 2018; SCHUMACHER et al., 2019; NASCIMENTO et al., 2020; SOARES et al., 2020), enquanto que quatro apresentaram resultados de equipamentos de desenvolvimento próprio ou com adaptações. Ainda, cinco grupos não informam precisamente sobre a origem do equipamento utilizado. Os dados de frequência citados, apresentam variação entre $0,1 \mathrm{~Hz}$ até $10 \mathrm{MHz}$. No entanto, há divergências de melhor valor, $30 \mathrm{kHz}$ ou $100 \mathrm{kHz}$, para respectivamente, Durante e colaboradores (2016) e Triphaty e colaboradores (2017). Para o grupo de Triphaty, o valor de impedância para o leite puro ficou entre 620 e $650 \Omega$. 
GELLER, et al.

Quadro 2. Metodologias utilizadas nos diferentes trabalhos

\begin{tabular}{|c|c|c|c|c|}
\hline Citação & Revista & Objetivo & Análise & Frequência \\
\hline $\begin{array}{l}\text { CHAKRAVBORTY e } \\
\text { BISWAS, } 2018\end{array}$ & IEEE Sensors Journal & $\begin{array}{l}\text { Identificar o limite mínimo detectável para cinco adulterantes } \\
\text { comuns no leite }\end{array}$ & $\begin{array}{l}\text { Adulteração: detergente, }\left(\mathrm{NH}_{4}\right)_{2} \mathrm{SO}_{4} \\
\quad \mathrm{NaOH} ; \mathrm{NaHCO}_{3} \mathrm{e} \mathrm{NaCl}\end{array}$ & $5,6 \mathrm{kHz}-500 \mathrm{~Hz}$ \\
\hline DAS et al., 2018 & IEEE Sensors Journal & $\begin{array}{l}\text { Detectar e quantificar de sabão, como adulterante, em leite, } \\
\text { empregando espectroscopia de impedância elétrica, variando os } \\
\text { parâmetros de impedância, capacitância, condutância e corrente. }\end{array}$ & $\begin{array}{l}\text { Adulteração: Sabão (concentrações - } \\
\quad 0,1 ; 0,3 ; 0,5 ; 0,7 \text { e } 0,9 \%)\end{array}$ & $100 \mathrm{~Hz}-1 \mathrm{MHz}$ \\
\hline DURANTE et al., 2016 & IEEE Sensors Journal & $\begin{array}{c}\text { Apresenta uma metodologia desenvolvida para a detecção de } \\
\text { adulteração de leite bovino por aplicação elétrica com medições } \\
\text { de impedância. }\end{array}$ & $\begin{array}{l}\text { Adulteração: } \mathrm{H}_{2} \mathrm{O}_{2} ; \mathrm{NaOH} \text { e formol } \\
\quad(\text { concentração }-1 ; 5 \text { e } 10 \%)\end{array}$ & $\begin{array}{c}10 \mathrm{kHz}-10 \mathrm{MHz} \\
\text { (melhor resultado } \\
\text { em } 30 \mathrm{kHz} \text { ) }\end{array}$ \\
\hline FARAHI et al., 2015 & Food Control & $\begin{array}{c}\text { Determinar paraquat no eletrodo de prata usando espectroscopia } \\
\text { de impedância eletroquímica (EIS). }\end{array}$ & $\begin{array}{l}\text { Contaminação química: herbicida } \\
\text { Paraquat }\end{array}$ & $\begin{array}{c}100 \mathrm{MHz}- \\
10 \mathrm{KHz}\end{array}$ \\
\hline GUPTA et al., 2017 & IEEE Sensors Journal & $\begin{array}{l}\text { Desenvolver um novo sensor de microeletrodo portátil baseado } \\
\text { em espectroscopia de impedância para a detecção de adulteração } \\
\text { no leite. }\end{array}$ & $\begin{array}{l}\text { Adulteração: detergente (concentrações } \\
-2 ; 4 ; 6 ; 8 \text { e } 10 \%)\end{array}$ & $\begin{array}{l}\text { faixa } 0,05-5,0 \mathrm{kHz} \\
\text { (melhor resultado } \\
\text { em } 4,75 \mathrm{kHz} \text { ) }\end{array}$ \\
\hline HUI e YING, 2017 & $\begin{array}{l}\text { ASABE (American Society of } \\
\text { Agricultural and Biological } \\
\text { Engineers) }\end{array}$ & $\begin{array}{l}\text { Avaliar um método de análise quantitativa rápida para detecção } \\
\text { de ofloxacina em leite cru usando reconhecimento específico de } \\
\text { molécula e uma técnica de espectro de impedância eletroquímica } \\
\text { (EIS) }\end{array}$ & $\begin{array}{l}\text { Contaminação química: antibiótico } \\
\text { ofloxacina }\end{array}$ & $1 \mathrm{kHz}$ \\
\hline $\begin{array}{l}\text { ISTAMBOULIÉ, G. et } \\
\quad \text { al, } 2016\end{array}$ & Talanta & $\begin{array}{c}\text { Desenvolver um sensor impedimétrico baseado na imobilização } \\
\text { covalente de aptâmeros em eletrodos impressos em tela } \\
\text { descartáveis após ativação do sal de diazônio }\end{array}$ & Composto biológico: aflatoxina M1 & $10 \mathrm{kHz}-1 \mathrm{~Hz}$ \\
\hline LOPES et al., 2017 & Food Anal. Methods & $\begin{array}{l}\text { Usar espectroscopia de impedância elétrica (EIS) e cálculo } \\
\text { fracionário para caracterizar leite ultra pasteurizado }\end{array}$ & $\begin{array}{l}\text { Físico-química: comparação entre tipos } \\
\text { de leite }\end{array}$ & $5 \mathrm{~Hz}-1 \mathrm{MHz}$ \\
\hline SOARES et al., 2020 & Food Chemistry & $\begin{array}{c}\text { Comparar resultados de processos analíticos químicos padrão e } \\
\text { espectroscopia de impedância eletroquímica (EIS) na } \\
\text { caracterização de diferentes bebidas }\end{array}$ & $\begin{array}{l}\text { Comparação: café moído; café solúvel; } \\
\text { substitutos do café; cevada; leite de vaca; } \\
\text { bebidas vegetais; chá; infusões de plantas } \\
\text { e misturas de plantas }\end{array}$ & $0,1 \mathrm{~Hz}-10 \mathrm{kHz}$ \\
\hline $\begin{array}{l}\text { SUDE e GHODINDE, } \\
2019\end{array}$ & $\begin{array}{l}\text { International Conference on } \\
\text { Trends in Electronics and } \\
\text { Informatics (ICOEI 2019) }\end{array}$ & $\begin{array}{l}\text { Realizar medidas de impedância elétrica em tempo real de } \\
\text { amostras de leite adulterados }\end{array}$ & Adulteração: água; ureia e amido & $\begin{array}{c}10 \mathrm{kHz} \text { a } 10 \mathrm{MHz} \\
\text { (melhor resultado } \\
\text { em } 90 \mathrm{kHz} \text { ) }\end{array}$ \\
\hline $\begin{array}{l}\text { BANCALARI,E. et al., } \\
\qquad 2016\end{array}$ & Frontiers in Microbiology & $\begin{array}{c}\text { Encontrar uma maneira objetiva de interpretar a significância } \\
\text { metabólica das curvas de impedância e propô-la como uma } \\
\text { abordagem válida para avaliar o desempenho acidificante } \\
\text { potencial de bactérias ácido-láticas iniciadoras a serem } \\
\text { empregadas na transformação do leite }\end{array}$ & $\begin{array}{c}\text { Microbiológico: Lactobacillus } \\
\text { helveticus; Lactobacillus delbrueckii } \\
\text { subsp. Bulgaricus; Lactococcus lactis; } \\
\text { Streptococcus thermophilus }\end{array}$ & \\
\hline
\end{tabular}


GELLER, et al.

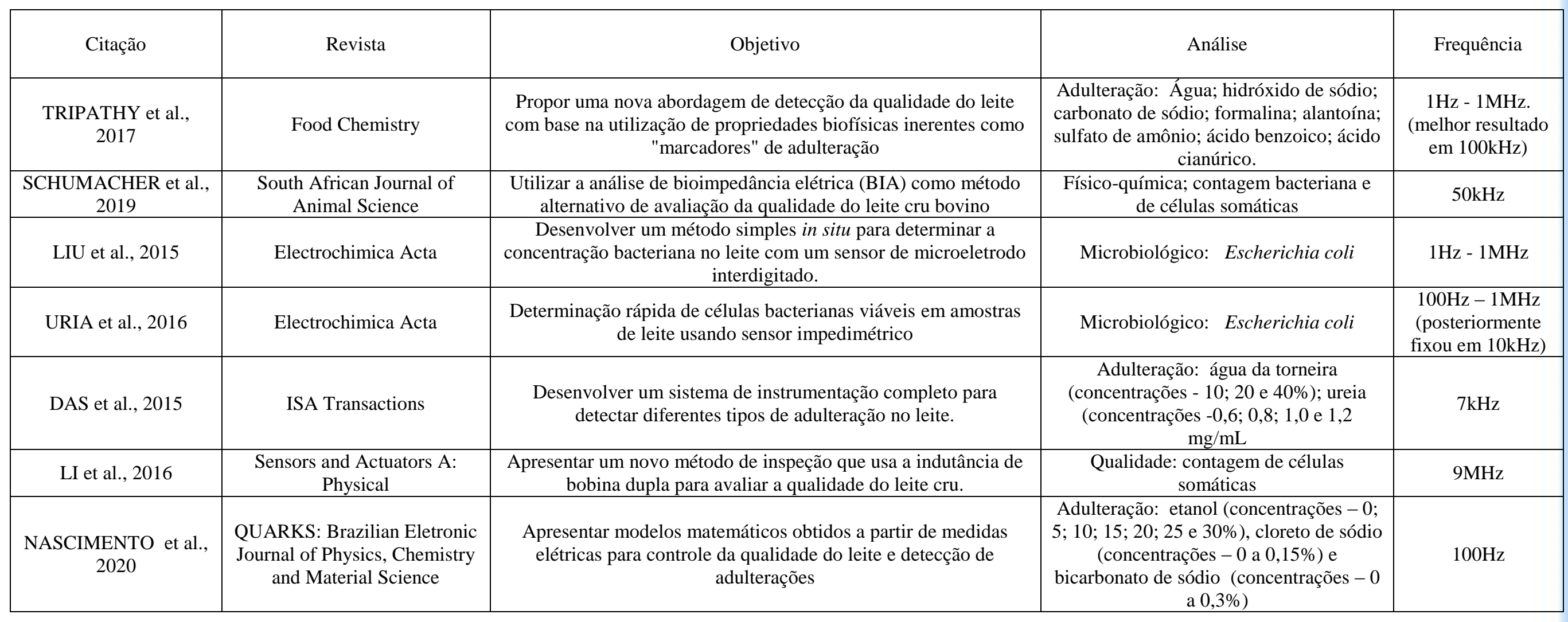




\subsection{Bioimpedância na análise físico-química e biológica do leite}

As características físico-químicas do leite podem ser alteradas devido às condições genéticas, nutricionais e ambientais das vacas, e de forma fraudulenta nos processos de obtenção, armazenamento, transporte e beneficiamento do leite (BERTOLINI; ROSSI, 2017), principalmente relacionadas à adição ou remoção de substâncias químicas próprias ou estranhas à sua composição (ABRANTES et al., 2014).

Lopes e colaboradores (2017) analisaram leite UHT integral, semi e desnatado e, ainda, leite cru semi e desnatado com redução e/ou fortificação dos teores de gordura, para simular amostras de leite usando especificações da espectroscopia por impedância elétrica, variando a frequência entre $5 \mathrm{~Hz}$ e $1 \mathrm{MHz}$, e o cálculo fracionário para caracterizar leite ultra pasteurizado. Os valores encontrados foram comparáveis aos determinados através dos métodos químicos padrão, revelando forte correlação entre as técnicas. Os resultados mostram que a espectroscopia de impedância elétrica e cálculo fracionário são capazes de modelar leite com um conjunto reduzido de parâmetros.

Chakraborty e Biswas (2018) variaram o percentual de gordura, entre 1,5 a 20\% com creme de leite em amostras de leite UHT integral, semi e desnatado que foram analisadas, através de um sensor de impedância, resultando em diversas medidas do ângulo da fase da impedância, sensíveis a concentração iônica do meio, pela presença de íons como $\mathrm{Na}^{+}, \mathrm{K}^{+}$e $\mathrm{Cl}^{-}$ e outros minerais presentes no leite.

$\mathrm{Na}$ avaliação da qualidade do leite bovino cru, os teores de proteína e gordura são os responsáveis por aumentar o valor agregado (RENTERO, 2018). Sob esta perspectiva a análise por bioimpedância elétrica foi utilizada para avaliar não somente a gordura, mas também através dos critérios: contagem de células somáticas (CCS), contagem bacteriana total (CBT), proteína, lactose, sólidos totais (ST) e sólidos não gordurosos (SNG), com resultados que demonstraram potencial para estimar a composição do leite, mas necessitando aumentar a precisão da técnica (SCHUMACHER et al., 2019).

É interessante ressaltar que foi possível determinar a qualidade de leite cru, através do controle de CCS, desta vez utilizando um chip de bobina dupla medindo a variação de fase para a indutância magnética, cujo equipamento apresenta um tamanho reduzido, baixo custo e com resposta rápida, ou seja, características desejáveis para análises de inspeção de rotina. Pela correlação proposta, os deslocamentos de fase medidos foram de $65^{\circ}$ a $86^{\circ}$, correspondendo a uma variação de CCS de 2 a 500kcel/mL (LI et al., 2016).

Cabe destacar, que apesar dos artigos ressaltarem seus objetivos em análises físicoquímicas de caracterização, é pelo controle destes parâmetros que as fraudes são descobertas e, 
por consequência, a técnica é recomendável para a confirmação de adulterações.

\subsection{Bioimpedância na avaliação de adulteração do leite}

Os adulterantes mais comuns no leite são: água, soro, leite desnatado, colostro, substâncias amiláceas, goma, sacarose, sal e outros leites (ABRANTES et al., 2014). Visando coibir fraudes e manter a qualidade do leite e seus derivados no Brasil, a instrução normativa n 30/2018, do MAPA, oficializa o Manual de Métodos Oficiais para Análise de Alimentos de Origem Animal (BRASIL, 2018). Detectar as fraudes mais comuns, implica na utilização de técnicas sofisticadas como: espectroscopia, eletroforese em gel, espectroscopia de absorção e cromatografia líquida (ABRANTES et al., 2014; FAGNANI, 2016; DAS et al., 2018), e por isto, a comunidade científica busca novas alternativas, preferencialmente mais rápidas e baratas para tal finalidade, como a bioimpedância.

Medições de impedância, para caracterizar adulteração de leite cru e UHT, com diferentes proporções de água potável, água deionizada, peróxido de hidrogênio $\left(\mathrm{H}_{2} \mathrm{O}_{2}\right)$, hidróxido de sódio $(\mathrm{NaOH})$ e formaldeído $\left(\mathrm{CH}_{2} \mathrm{O}\right)$ foram realizadas por Durante e colaboradores (2016). As amostras foram analisadas eletricamente aplicando as medições de espectroscopia de impedância elétrica em um sistema microcontrolado, permitindo um monitoramento em tempo real. Uma classificação dos resultados foi proposta usando um algoritmo de k-vizinhos mais próximos que permitiu qualificar quantitativamente as amostras em termos de pureza e adulteração.

Também Chakraborty e Biswas (2018) variaram o percentual de gordura, entre 1,5 a $20 \%$ com creme de leite em amostras de leite UHT integral, semi e desnatado, e assim, testaram os adulterantes $\left(\mathrm{NaOH}, \mathrm{NaHCO}_{3},\left(\mathrm{NH}_{4}\right)_{2} \mathrm{SO}_{4}\right.$ e $\left.\mathrm{NaCl}\right)$ através de um sensor de impedância, sensível a concentração iônica do meio de medição, dando diferentes ângulo de fase da impedância. Conforme a concentração iônica da solução, a difusão destes íons se altera, refletindo na variação do valor de medida da impedância. O sensor de bioimpedância, obteve um baixo limite de detecção para os adulterantes testados: 1g/L para $\left(\mathrm{NH}_{4}\right)_{2} \mathrm{SO}_{4}$ e $\mathrm{NaCl}$ e $2 \mathrm{~g} / \mathrm{L}$ para $\mathrm{NaOH}$ e $\mathrm{NaHCO}_{3}$.

É considerado fraude intencional a adição de substâncias alcalinas, como o sabão, no leite, com o intuito de aumentar a conservação ou diminuir a acidez, como também amido ou ureia para aumentar a densidade, fazendo a reconstituição da mesma, em caso de adição de água (ABRANTES et al., 2014). Existem muitas formas de se adulterar o leite, por isto, Tripathy e colaboradores (2017) propuseram em seu trabalho, a adoção de marcadores combinados, ou seja, de um laboratório multiplexado em plataforma de chip para avaliar os seguintes 
adulterantes em leite: água da torneira, $\mathrm{NaOH}, \mathrm{NaCO}_{3},\left(\mathrm{NH}_{4}\right)_{2} \mathrm{SO}_{4}$, formol, ureia, ácido benzóico e ácido cianúrico. A adulteração com multicomponentes é uma prática comum sendo monitorada por estes autores a partir das mudanças na condutividade elétrica e no $\mathrm{pH}$ do leite, sendo que a padronização do leite puro foi feita com a espectroscopia de impedância com eletrodo de trabalho de carbono vítreo e contador de platina/eletrodo de referência, a um potencial de $0,3 \mathrm{~V}$ e na faixa de frequência de $1 \mathrm{~Hz}-1 \mathrm{MHz}$. Como resultado, verificaram que a combinação de dois dados é eficiente para detectar a adulteração do leite, por exemplo, impedância e pH, para casos de fraudes com adição de ácido salicílico $(4 \mathrm{mg} / \mathrm{mL})$ e posterior calibração de pH com a adição de $\mathrm{NaOH}$. Apesar dos valores de pH estarem conforme o padrão recomendado, a amostra foi identificada como "adulterada" monitorando as mudanças na impedância elétrica.

Também neste sentido, foi verificado a adulteração de leite com amido e detergente, através de um micro sensor baseado na espectroscopia de impedância. Os resultados indicaram variação no valor de impedância para diferentes concentrações de amido e detergente nas amostras, variando a faixa de frequência de $0,05-5,0 \mathrm{kHz}$. A impedância da amostra de leite de referência em frequência $4,75 \mathrm{kHz}$ foi considerada $8,01 \times 10^{2} \Omega$, já a amostra de leite adulterada com $10 \%(\mathrm{p} / \mathrm{v})$ de detergente teve um valor $56 \%$ do valor original, enquanto a impedância de amostra de leite adulterada com $10 \%(\mathrm{p} / \mathrm{v})$ de amido apresentou um valor $160 \%$ maior do valor de referência (GUPTA et al., 2017).

O trabalho desenvolvido por Das e colaboradores (2018), através da detecção on-chip empregando a espectroscopia de impedância, determinou a adulteração de leite bovino com $0,1 \% ; 0,3 \% ; 0,5 \% ; 0,7 \%$ e $0,9 \%(\mathrm{~m} / \mathrm{m})$ de sabão, avaliando a variação dos parâmetros elétricos: impedância, capacitância, condutância e corrente. Os autores observaram que a capacitância, a condutância e a corrente aumentam, ao passo que a impedância diminui com o aumento do teor de sabão no leite, sendo que o coeficiente de sensibilidade foi explicado em termos dos valores de condutância medidos.

Sude e Ghondinde (2019) através de um circuito em série, medindo os valores de impedância conseguiram classificar quantitativamente o leite adulterado com água, ureia e amido. Os autores perceberam que este tipo de adulteração altera principalmente a parte resistiva da impedância elétrica. A frequência de $90 \mathrm{kHz}$ se mostrou a melhor opção para examinar a adulteração do leite, pois o sensor funciona como um elemento de fase constante. Observaram também, que conforme a concentração de adulteração do leite aumenta, o valor da tensão diminui, assim como a condutividade e o valor de $\mathrm{pH}$. 


\subsection{Bioimpedância na avaliação microbiológica}

A impedância na microbiologia, principalmente em análise de alimentos, já tem sido pesquisada desde os anos 70. Além da aplicação da bioimpedância, que é comumente utilizado para análise do controle e quantificação microbiana, pesquisas também têm sido realizadas com o intuito de avaliação da atividade metabólica bacteriana (BANCALARI et al., 2016). Liu e colaboradores (2015) utilizaram um sensor de impedância com microeletrodos interdigitados para determinar a contaminação bacteriana in situ, ou seja, em fazendas, laticínios e plantas de processamento como uma ferramenta de controle de qualidade. Os pesquisadores testaram uma variação de frequência entre $1 \mathrm{~Hz}$ a $1 \mathrm{MHz}$, no entanto, concluíram que o crescimento bacteriano causa mudança mensurável entre as frequências de $1 \mathrm{~Hz}-10 \mathrm{kHz}$ (baixa frequência). Diante disso, determinaram o tempo de detecção (necessário para atingir uma mudança de impedância de $10 \%$ ) em $10 \mathrm{~Hz}$, conseguindo detectar a presença de Escherichia coli no leite na concentração de 7células/mL. O sistema testado mostrou ser eficiente e com alta sensibilidade para detectar

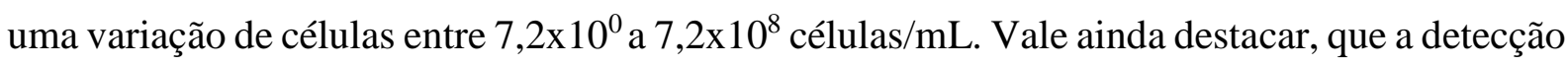
bacteriana foi possível sem a necessidade de fazer enriquecimento do leite para o crescimento da E. coli.

No ano seguinte, Uria e colaboradores (2016) também publicaram resultados relacionando o crescimento de E. coli com as alterações de impedância associadas à acidificação do meio de cultivo, mas na frequência de $10 \mathrm{kHz}$. Diferentemente do estudo de Liu e colaboradores (2015), os autores tiveram que enriquecer a amostra de leite. O sistema apresentou menor sensibilidade de detecção comparado ao trabalho anterior, conseguindo detectar uma concentração de E. coli em uma faixa de $10^{2}$ a $10^{6} \mathrm{UFC} / \mathrm{mL}$ em 6 horas de incubação (margem de erro de 5-12\%). Uma das conclusões dos autores foi que as alterações dependem do número de microrganismos na amostra, uma vez que para detectar as mudanças elétricas é necessário a mudança de $\mathrm{pH}$ devido ao metabolismo bacteriano.

Em um estudo utilizando um sistema comercial de análise microbiológica BacTrac 4300 $\mathrm{R}$, sob influência de quatro diferentes temperaturas, mostrou a capacidade de avaliar a cinética de crescimento utilizando curvas de impedância. Foram utilizados no estudo supracitado quatro espécies de bactérias lácticas, Lactobacillus helveticus, Lactobacillus delbrueckii subsp. bulgaricus, Lactococcus lactis e Streptococcus thermophilus totalizando 80 isolados, diluídas de 10 a 100.000 vezes (BANCALARI et al., 2016). Os autores também propuseram uma possibilidade, através da utilização da impedância, de avaliar o potencial de acidificação de bactérias lácticas starter, utilizadas na transformação do leite, indicando novos potenciais de 
aplicação da técnica na produção de leite fermentado e queijo, principalmente queijos cozidos e semi-cozidos.

\subsection{Bioimpedância na avaliação de contaminação de resíduos químicos e compostos biológicos}

A técnica de impedância também tem sido aplicada na detecção de contaminação de resíduos químicos e compostos biológicos como toxinas produzidas por microrganismos. Farahi e colaboradores (2015) detectaram o herbicida Paraquat em amostra de leite utilizando impedância eletroquímica. Os autores conseguiram uma resposta da metodologia na faixa de detecção entre $1,0 \times 10^{-14}$ a 8,0x $10^{-4} \mathrm{~mol} / \mathrm{L}$, com uma repetibilidade de $1,03 \%$ considerando $\mathrm{n}=8$. Dê forma conclusiva, o método pode ser amplamente aplicado, desde que em condições de trabalho otimizadas, para determinar ultra traços do herbicida Paraquat, na ordem de 7,37x10${ }^{16} \mathrm{~mol} / \mathrm{L}$, com boa sensibilidade.

Um ano após o sucesso da pesquisa na detecção do herbicida Paraquat, um outro grupo de pesquisadores projetaram um aptasensor e conseguiram detectar a presença de aflatoxina M1 (AFM1) em leite através da espectroscopia de impedância eletroquímica. Para a detecção foi necessário um tratamento preliminar das amostras de leite usando uma extração simples (líquido-líquido), seguida de uma filtração através de membrana de PTFE de 0,2mm (ISTAMBOULIÉ et al., 2016). Concluiu-se que o sistema desenvolvido foi capaz de detectar AFM1 entre 20 e 1000ng/kg que são compatíveis com os níveis de contaminação natural.

Outro composto que também foi alvo de pesquisa com aplicação da técnica de impedância foi a ofloxacina (HUI e YING, 2017). Neste estudo, os autores objetivaram investigar um método de análise quantitativa rápida da concentração de ofloxacina em leite cru, em uma frequência de $1 \mathrm{kHz}$, e criaram um modelo com base nos autovalores da relação sinalruído máximos da técnica de impedância eletroquímica. Hui e Ying (2017) concluíram que o método apresentou alta acurácia, repetibilidade e recuperação (recuperação das amostras variou de $88,2 \%$ a $94 \%$ ), equivalente a precisão de uma análise de cromatografia líquida de alta eficiência (HPLC). Comparativamente, o maior erro da técnica de impedância eletroquímica com HPLC foi de $1,22 \%$ e da técnica isolada de $0,67 \%$.

\section{Considerações Finais}

O levantamento e a análise sistemática dos trabalhos com a temática bioimpedância em leite, não pretendeu esgotar o assunto, ou fazer uma revisão da técnica em sua totalidade, mas adveio de uma proposta de evidenciar a versatilidade de aplicação da técnica. Nos últimos 5 
anos, foi possível perceber o desenvolvimento da bioimpedância como alternativa, em diversas áreas da ciência dos alimentos. Para o leite, especialmente, tem se mostrado promissora para em análises físico-químicas, monitoramento de diversos agentes adulterantes e ainda, no controle microbiológico. Contudo, a utilização da bioimpedância, como técnica para análise de rotina na indústria leiteira, apesar da rapidez e custo baixo, ainda carece de consolidação, que com certeza virá através do desenvolvimento de maiores pesquisas.

\section{Referências}

ABRANTES, M. R., CAMPÊLO C. S.; SILVA J. B. A., 2014. Fraude em leite: Métodos de detecção e implicações para o consumidor. Revista Instituto Adolfo Lutz, v 73(3). p 244-251, 2014.

AL-ALI, A. A.; ELWAKIL, A.S.; MAUNDY, B.J. Bio-impedance Measurements with Phase Extraction using the Kramers-Kronig transform: Application to Strawberry Aging. In: IEEE 61st International Midwest Symposium on Circuits and Systems (MWSCAS), 2018, Windsor, 468 p.

BAKR, A. A.; RADWAN, A. G.; MADIAN, A. H.; ELWAKIL, A. S. Aging effect on apples bio-impedance using AD5933. In: 3rd IEEE Int. Conf. on Advances in Computational Tools for Engineering Applications (ACTEA), 2016, Beirute, 161 p.

BANCALARI, E.; BERNINI, V.; BOTTARI, B., NEVIANI, E.; GATTI, M., 2016. Application of Impedance Microbiology for Evaluating Potential Acidifying Performances of Starter Lactic Acid Bacteria to Employ in Milk Transformation. Frontiers in Microbiology, v 7 (1628) p. 111, 2016.

BERTOLINI, A. B.; ROSSI, G. A. M., 2017. Análises físico-químicas e detecção de fraudes em leite tratado termicamente por Ultra Alta Temperatura (UAT) comercializado na Região Centro-Oeste do Estado de São Paulo, Brasil. Revista Brasileira de Higiene e Sanidade Animal, v 11(4). p. $374-381,2017$.

BRASIL. Ministério da Agricultura, Pecuária e Abastecimento. Portaria n 146, de 07 de março de 1996. Aprova os Regulamentos Técnicos de Identidade e Qualidade dos Produtos Lácteos. Diário Oficial da União: seção 1, Brasília, DF, p. 3977, de 11 mar. 1996. Disponível em: http://extranet.agricultura.gov.br/sislegis-

consulta/consultarLegislacao.do?operacao=visualizar\&id=1218. Acesso em: 29 jul. 2020.

BRASIL. Ministério da Agricultura, Pecuária e Abastecimento. Portaria $n^{\circ} 370$, de 04 de setembro de 1997. Aprova a Inclusão do Citrato de Sódio no Regulamento Técnico para Fixação de Identidade e Qualidade do Leite U.H.T (U.A.T). Diário Oficial da União: seção 1, Brasília, DF, p. 19700, de 08 set. 1997. Disponível em: http://extranet.agricultura.gov.br/sislegis-

consulta/consultarLegislacao.do?operacao=visualizar\&id=1252. Acesso em: 29 jul. 2020. 
BRASIL. Ministério da Agricultura, Pecuária e Abastecimento. Manual de métodos oficiais para análise de alimentos de origem animal / Ministério da Agricultura, Pecuária e Abastecimento. Secretaria de Defesa Agropecuária. - Brasília : MAPA, 2017. 140 p. ISBN 978-85-7991-111-8. Disponível em: https:/www.gov.br/agricultura/ptbr/assuntos/laboratorios/legislacoes-emetodos/poa/Manualdemtodosoficiaisparaanlisedealimentosdeorigemanimalled.rev_.pdf. Acesso em: 28 jul. 2020.

BRASIL. Ministério da Agricultura, Pecuária e Abastecimento. Instrução Normativa $n^{\circ}$ 30, de 26 de junho de 2018. Oficializa o Manual de Métodos Oficiais para Análise de Alimentos de Origem Animal. Diário Oficial da União: seção 1, Brasília, DF, n. 134, p. 9, 13 jul. 2018. Disponível em: http://www.in.gov.br/materia//asset_publisher/Kujrw0TZC2Mb/content/id/29896222/do1-2018-07-13-instrucao-normativan-30-de-26-de-junho-de-2018-29896212. Acesso em: 28 jul. 2020.

BRITO, M. A.; BRITO, J. R.; ARCURI, E.; LANGE, C.; SILVA, M.; SOUZA, G.. Composição. In: Agência de Informação Embrapa: Agronegócio do Leite. Disponível em: https://www.agencia.cnptia.embrapa.br/Agencia8/AG01/arvore/AG01_128_21720039243.ht ml. Acesso em: 28 jul. 2020.

CHAKRABORTY, M.; BISWAS, K., 2018. Limit of detection for five common adulterants in milk: A study with different fat percent. IEEE Sensors Journal, v 18(6). p. 2395 - 2403, 2018.

DAS, S.; SIVARAMAKRISHNA, M.; BISWAS, K.; GOSWAMI, B., 2015. A low cost instrumentation system to analyze different types of milk adulteration. ISA transactions, $v 56$. p. 268-275, 2015.

DAS, C.; CHAKRABORTY, S.; KARMAKAR, A.; CHATTOPADHYAY, S. On-chip Detection and Quantification of Soap as an Adulterant in Milk Employing Electrical Impedance Spectroscopy. In: International Symposium on Devices, Circuits and Systems (ISDCS), Howrah, 2018, 1-4 p. DOI: http://dx.doi.org/10.1109/ISDCS.2018.8379634.

DEAK, T.; BEUCHAT, L. R., 1993. Comparison of conductimetric and traditional plating techniques for detecting yeasts in fruit juices. Journal of applied bacteriology, $v$ 75(6). p. 546-550, 1993.

DURANTE, G.; BECARI, W.; LIMA, F. A. S.; PERES, E. M., 2016. Electrical Impedance Sensor for Real-Time Detection of Bovine Milk Adulteration. IEEE Sensors Journal, v 16(4). p.861-865, 2016.

EL KHALED, D.; CASTELLANO, N.N.; GAZQUEZ, J.A.; GARCIA SALVADOR, R.M.; MANZANO_AGUGLIARO, F., 2017. Cleaner quality control system using bioimpedance methods: a review for fruits and vegetables. Journal of Cleaner Production, v 140. p. 17491762, 2017.

FARAHI, A.; EL GAINI, L.; ACHAK, M.; EL YAMANI, S.; EL MHAMMEDI, M. A.; BAKASSE, M., 2015. Interaction study of paraquat and silver electrode using electrochemical impedance spectroscopy: Application in milk and tomato samples. Food Control, v 47. p. 679685, 2015. 
FARGNANI, R. As principais fraudes em leite. Publicado em 13/06/2016. Disponível em: https://www.milkpoint.com.br/colunas/rafael-fagnani/principais-fraudes-em-leite100551n.aspx. Acesso em: 29 jul. 2020.

FREEBORN, T. J.; ELWAKIL, A. S. \& MAUNDY, B., 2017. Variability of Cole-model bioimpedance parameters using magnitude-only measurements of apples from a two-electrode configuration, International Journal of Food Properties, 20:sup1, S507-S519, 2017.

GUPTA, R.; WADHWA, S.; MATHUR, A.; DUBEY, K. A., 2017 Designing of a Microelectrode Sensor based Label Free Milk Adulteration Testing System (MATS). IEEE Sensors Journal, v 17(18). p. 6050-6055, 2017.

GRIMNES, S.; MARTINSEN, O. G. Bioimpedance and bioelectricity basics. London: UKAcademic press, 2000.

QUILlFELDT, J. A. Origem dos Potenciais Elétricos das Células Nervosas. [S.1.]: Departamento de Biofísica - UFRGS, 2005. Disponível em: http://www.ufrgs.br/biofisica/Bio10004/JAQuillfeldt_OrigPotsEletrCelNervs_poligrafo2005. pdf. Acesso em: 25 ago. 2018.

HUI, G.; YING, Y., 2017. Quantitative rapid analysis method for ofloxacin in raw milk based on molecule-specific recognition and electrochemical impedance spectrum. Transactions of the ASABE, v60(5). p. 1439-1443, 2017.

HOLDER, D. Electrical Impedance Tomography: Methods, history and applications. London: Institute of Physics Publishing, 2004.

ISTAMBOULIÉ, G.; PANIEL, N.; ZARA, L.; GRANADOS, L. R.; BARTHELMEBS, L.; NOGUER, T., 2016. Development of an impedimetric aptasensor for the determination of aflatoxin M1 in milk. Talanta, v146. p. 464-469, 2016.

LI, W.; LIAO, S.; TSOU, C., 2016. A novel sensing chip with dual-coil inductance for determining raw milk quality. Sensors and Actuators A, v241. p. 96-103, 2016.

LIU, J.; SETTU, K.; TSAI, J.; CHEN, C., 2015. Impedance sensor for rapid enumeration of E. coli in milk samples. Electrochimica Acta, v 182. p. 89-95, 2015.

LOPES, A.M.; MACHADO, J.A.T.; RAMALHO, E.; SILVA, V., 2017. Milk Characterization Using Electrical Impedance Spectroscopy and Fractional Models. Food Analytical Methods, v 11(3). p. 901-912, 2017.

MILKPOINT. Levantamento TOP 100 2020: os 100 maiores produtores de leite do Brasil. 2020. Disponível em: https://www.milkpoint.com.br/top100-2020-lp/. Acesso em: 28 julho 2020 .

MORO, L. C.; PORTO, R. W. Single frequency electrical impedance tomography system with offline reconstruction algorithm. In: IEEE 6th Latin American Symposium on Circuits \& Systems (LASCAS), 2015, Montevidéu. p. 1-4, 2015. 
NASCIMENTO, W L.; ANJOS, L.; BELL, V.; JOSÉ, M., 2020 Mathematical models for correlating electrical parameters and milk adulterants. QUARKS: Brazilian Electronic Journal of Physics, Chemistry and Materials Science, v 2(1). p. 27-33, 2020.

NEAVES, P.; WADDELL, M. J.; PRENTICE, G. A., 1988. A medium for the detection of Lancefield Group D cocci in skimmed milk powder by measurement of conductivity changes. Journal of Applied Bacteriology, v 65(6). p. 437-448, 1988.

OLIVEIRA, K. B.; KOBORI, C. N.; UBALDO, J. C. S. R., 2019. Avaliação da qualidade físico-química, rotulagem e ocorrência de adulterações em amostras de leite UHT. Revista do Instituto de Laticínios Cândido Tostes, v 74(3). p. 195-206, 2019.

PORTO, R. W. Projeto e avaliação de um canal de medição de bioimpedâncias. Orientador: Adalberto Schuck Jr. 2009. 124 f. Dissertação (Mestrado em Engenharia Elétrica) Departamento de Engenharia Elétrica, Universidade Federal do Rio Grande do Sul, Porto Alegre, 2009.

PORTO, R. W.; AYRES, L. C.; NEUENFELD, R. H.; CARVALHO, C. W.; GELLER, A. M.; OLIVEIRA, W. C. Electrical Bioimpedance Scanning in Bacterial Diagnosis and Mastitis Detection. In: IEEE International Instrumentation and Measurement Technology

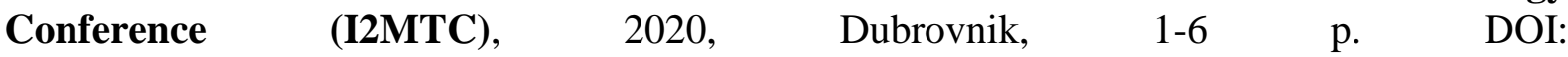
httpx://dx.doi.org/10.1109/I2MTC43012.2020.9129159.

PEREIRA, R. M. Desenvolvimento de um sistema de espectroscopia de impedância elétrica multicanal. Orientador: Pedro Bertemes Filho. 2009. 116 f. Dissertação (Mestrado Profissional em Engenharia Elétrica) Universidade do Estado de Santa Catarina, Joinville 2009.

PLIQUETT, U., 2010 Bioimpedance: a review for food processing. Food Engineering Reviews, v 2(2). p. 74-94, 2010.

RENTERO, N. Anuário Leite 2018: Indicadores, tendências e oportunidades para quem vive no setor leiteiro. Disponível em: https://www.embrapa.br/busca-de-publicacoes//publicacao/1094149/anuario-leite-2018-indicadores-tendencias-e-oportunidades-para-quemvive-no-setor-leiteiro. Acesso em: 28 julho 2020.

RUSSELL, S. M.; FLETCHER, D. L.; COX, N. A., 1994. The effect of incubation temperature on recovery of mesophilic bacteria from broiler chicken carcasses subjected to temperature abuse. Poultry science, v 73(). p. 1144-1148, 1994.

SANCHEZ, B.; VANDERSTEEN, G.; BRAGOS, R.; SCHOUKENS, J., 2011. Optimal multisine excitation design for broadband electrical impedance spectroscopy. Measurement Science and Technology, v 22(11). p. 115601, 2011.

SCHUMACHER, L.L.; VIÉGAS, J.; NAETZOLD, S.; TONIN, T. J.; ROCHA, L.; CAUDURO, L.; MORO, A.B.; ROBALO, S. S., 2019. Use of electrical bioimpedance analysis to evaluate the quality of bovine raw milk. South African Journal of Animal Science, v 49(3). p. 727-734, 2019. 
SUDE, M.; GHODINDE, K. Electrical impedance Sensor for Real-Time Detection of Urea and Starch in Milk. In: Proceedings of the Third International Conference on Trends in Electronics and Informatics (ICOEI 2019), IEEE 2019, ISBN: 978-1-5386-9439-8, 2019.

TAKA, E. N. Transvarredura por Bioimpedância: uma ferramenta para detecção precoce de câncer de mama em mulheres jovens. Orientadores: Márcio Nogueira de Souza Alexandre Visintainer Pino. 2008. 131 f. Dissertação. (Programa de Pós-graduação em Engenharia Biomédica) Universidade Federal do Rio de Janeiro, Rio de Janeiro, 2008.

TRIPATHY, S.; GHOLE, A.; KHANDAVALLI, D.; VANJARI, S.; SINGH, S., 2016. A comprehensive approach for milk adulteration detection using inherent bio-physical properties as 'Universal Markers': Towards a miniaturized adulteration detection platform. Food Chemistry. v 217. p. 756-765, 2016.

URIA, N.; MORAL-VICO, J.; ABRAMOVA, N.; BRATOV, A.; MUÑOZ, F. X., 2016. Fast determination of viable bacterial cells in milk samples using impedimetric sensor and a novel calibration method. Electrochimica Acta, v 198. p. 249-258, 2016.

YÚFERA, A.; CAÑETE, D.; DAZA, P. A microelectrode-cell sensor model for real time monitoring. In.: SENSORDEVICES 2011: The Second International Conference on Sensor Device Technologies and Applications, v 1.p. 143 - 146, 2011. 